\title{
EFEITO DE DIFERENTES DOSAGENS DE VITAMINA A INJETÁVEL NA PRODUÇÃO E QUALIDADE DE EMBRIÕES BOVINOS DA RAÇA NELORE
}

\author{
Effect of different dosages of vitamin A injection on production and quality of cattle embryos
}

\author{
Bruno Cesar do Amaral ${ }^{1}$, José Camisão de Souza ${ }^{2}$, Antônio Gilberto Bertechini ${ }^{3}$, \\ Ana Tereza de Mendonça Viveiros ${ }^{4}$, Júlio César Teixeira ${ }^{5}$, Alexandre Francisco Amaral Arantes ${ }^{6}$
}

\begin{abstract}
RESUMO
Conduziu-se este trabalho com o objetivo de avaliar o efeito de quatro diferentes doses de vitamina A $(0$ - $(\mathrm{n}=14)$, $500.000(\mathrm{n}=15), 1.000 .000(\mathrm{n}=17)$ e $1.500 .000(\mathrm{n}=16)$ (UI) (na forma de palmitato de retinol) na produção e qualidade de embriões coletados de vacas doadoras da raça nelore $(n=64)$. O experimento foi realizado na Central de Transferência de Embriões Cauembryo no município de Funilândia - MG. As vacas foram superovuladas no $10^{\circ}(\mathrm{n}=18), 11^{\circ}(\mathrm{n}=10), 12^{\circ}(\mathrm{n}=26)$ ou $13^{\circ}$ $(\mathrm{n}=10)$ dia após a data do cio com $20 \mathrm{ml}$ de Folltropin ${ }^{\circledR}$ (Vetrepharm, Belleville, Canada) ou $10 \mathrm{ml}$ Pluset® (I.F. Serono, Roma, Itália) distribuídos em dosagens decrescentes durante quatro dias, em duas aplicações diárias (intercaladas de doze horas). Os tratamentos com vitamina A foram iniciados juntamente com a primeira dose de FSH. A luteólise foi induzida no quarto dia do tratamento de FSH com uma aplicação de 0,75 mg de cloprostenol sódico (Ciosin®), Coopers do Brasil, São Paulo, Brasil) e as doadoras observadas em cio foram inseminadas às 12 e 24 horas após o seu início, usando sêmen de diferentes touros. As análises estatísticas foram feitas utilizando o procedimento GENMOD do SAS (SAS INSTITUTE, 1995). O número de embriões viáveis aumentou significativamente $(\mathrm{P}<0,0001)$, apresentando valores de 3,6; 6,1; 6,5 e 6,7 para as dosagens de 0, 500.000, 1.000 .000 e 1.500.000 UI de vitamina A, respectivamente. A porcentagem de embriões viáveis também aumentou $(\mathrm{P}<0,01)$, resultando nos valores de $51 \%, 57 \%, 63 \%$ e $60 \%$ para o aumento crescente das doses de vitamina A aplicadas. Já o número de estruturas recuperadas não foi diferente $(\mathrm{P}>0,05)$ entre as doadoras suplementadas $(9,5,8,3$ e 10,5, respectivamente para 500.000, 1.000 .000 e 1.500 .000 UI de vitamina A) e não-suplementadas $(8,2)$. Por meio desses dados, verifica-se que a suplementação de vitamina A injetável antes da coleta melhora a qualidade dos embriões coletados, sem interferir na quantidade de estruturas produzidas.
\end{abstract}

Termos para indexação: Vitamina A, superovulação, embriões bovinos, transferência de embriões, nutrição animal, reprodução.

\begin{abstract}
The objective was to evaluate the effect of four different dosages of retinol palmitate $0-(n=14), 500,000(n=15)$, $1,000,000(\mathrm{n}=17)$ and 1,500,000 $(\mathrm{n}=16)$ International Units (IU) of vitamin A in the form of retinol palmitate on production and quality of embryos recovered from Nelore donor cows $(n=64)$. The experiment was carried out in the Embryo Transfer Company Cauembryo in the county of Funilândia - MG. Cows were superovulated on the $10^{\text {th }}(n=18), 11^{\text {th }}(n=10), 12^{\text {th }}(n=26)$ or $13^{\text {th }}$ $(n=10)$ days after estrus onset with an injection of $20 \mathrm{ml}$ of Folltropin ${ }^{\circledR}$ (Vetrepharm, Belleville, Canada) or $10 \mathrm{ml}$ of Pluset ${ }^{\circledR}$ (I.F. Serono,Roma, Itália) administered in decreasing doses for four days twice daily (each $12 \mathrm{~h}$ ). Vitamin A injection was delivered with the first FSH injection. Luteolysis was induced on the $4^{\text {th }}$ day of FSH treatment by giving $0.75 \mathrm{mg}$ of sodium cloprostenol (Ciosin ${ }^{\circledR}$, Coopers do Brasil, São Paulo, Brasil) and donors observed in estrus were artificially inseminated 12 and 24 hours after the onset of estrus using semen of different bulls of proven fertility. Statistical analysis was carried out using the GENMOD procedure of SAS (SAS INSTITUTE, 1995). The number of viable embryos differed $(\mathrm{P}<0.0001)$, between control (3.6), and 500,000 (6.1), 1,000,000 (6.5) and 1,500,000 (6.7) vitamin A treatments. Percentage of viable embryos also increased $(\mathrm{P}<0.01)$, from 0.51 in the control, to $0.57,0.63$ and 0.60 in order of increasing Vitamin A treatment groups, respectively. Number of total structures recovered (ER) was not different between supplemented $(9.5,8.3$ and 10.5 respectively for 500,000, $1,000,000$ e 1,500,000 IU of vitamin A) and not supplemented (8.2). These results indicate that supplementation of vitamin A i.m. before flushing improves embryo quality without interfere in the quantity of embryos recovered.
\end{abstract}

Index terms: Vitamin A, superovulation, cattle embryos, embryo transfer, animal nutrition, reproduction.

(Recebido para publicação em 17 de março de 2003 e aprovado em 23 de junho de 2003)

\footnotetext{
1. Zootecnista, Mestre em Produção Animal pela Universidade Federal de Lavras/UFLA - Caixa Postal 37 - 37200-000 - LAVRAS, MG.

2. Médico Veterinário, PhD., Professor do Departamento de Zootecnia da UFLA.

3. Zootecnista, DSc., Professor do Departamento de Zootecnia da UFLA.

4. Médica Veterinária, PhD., Professor do Departamento de Zootecnia da UFLA.

5. Zootecnista, Pos-Doctor, Professor do Departamento de Zootecnia da UFLA.

6. Médico Veterinário, aluno do Curso de Mestrado do Departamento de Zootecnia da UFLA.
} 


\section{INTRODUÇÃO}

A seleção genética em bovinos proporcionou animais com alta produção de leite e carne. No entanto, em condições naturais, os animais conseguem produzir, no máximo, uma cria por ano. A multiplicação mais efetiva de animais geneticamente superiores implica na necessidade de promover múltiplas ovulações como ferramenta importante para aumentar a produção de embriões. Quanto maior o número de embriões viáveis produzidos, maior será o número de crias geradas por ano. Juntamente com a superovulação, vários fatores contribuem para as variáveis produção e qualidade de embriões. Entre eles, os fatores nutricionais são expressivos e seus efeitos na superovulação são pouco entendidos (YAAKUB et al., 1999). Entre os fatores nutricionais, a vitamina A destacase e sua importância na reprodução animal é bem conhecida (MCDOWELL, 1989). A suplementação de vitamina A i.m. na dosagem de 1.000.000 UI de palmitato de retinol melhora a qualidade de embriões bovinos (SHAW et al., 1995). A resposta na qualidade de embriões também foi encontrada em programas de transferência de embriões em ratas suplementadas com vitamina A (ELMARIMI et al., 1990), em bovinos suplementados com abóbora (AMARAL et al., 2001) e ovinos suplementados com vitamina A (EBERHARDT et al., 1999).

Maiores concentrações intrafoliculares de vitamina A estão positivamente relacionadas à qualidade folicular (SCHWEIGERT et al., 1988), o que sugere que essa vitamina pode ser um dos principais fatores controladores do recrutamento, seleção e crescimento dos folículos dominantes em bovinos (SCHWEIGERT e ZUCKER, 1988). Além disso, a vitamina A modula a síntese da enzima de clivagem da cadeia lateral do colesterol - P450 SCC (HAYES, 1971; COREY e HAYES, 1972; JAYARAM et al., 1973; GANGULY et al., 1980), aumentando a produção de pregnenolona a partir do colesterol. Ela ainda modula a atividade da enzima $\Delta^{5}-3 \beta$-hidroxiesteróide desidrogenase (JUNEJA et al., 1966; ISLABÃO, 1982) aumentando a conversão de pregnenolona em progesterona. Como maiores concentrações de progesterona estão associadas à melhor qualidade embrionária (DYCK et al., 1980; PHARAZYN et al., 1991; JINDAL et al., 1996; WHALEY et al., 1997), espera-se que sua demanda em vacas superovuladas seja maior e que, então, a suplementação seja uma proposta viável. Sugere-se que a progesterona possa aumentar a produção da RBP uterina, o que possivelmente aumenta o suporte nutricional do embrião (THOMAS et al., 1992), estendendo o possível efeito benéfico da suplementação.
Não há informação na literatura sobre o efeito de diferentes dosagens de vitamina A na produção e qualidade de embriões bovinos. Além disso, há escassez de trabalhos que avaliam efeito nutricional, especialmente vitamina $\mathrm{A}$, na superovulação de bovinos. O presente trabalho, tem como objetivo principal avaliar o efeito de diferentes dosagens de vitamina A injetável sobre a quantidade e qualidade de embriões produzidos.

\section{MATERIAL E MÉTODOS}

O experimento foi realizado na Central de Transferência de Embriões Cauembryo, no município de Funilândia, Minas Gerais, no período de junho a setembro de 2002. Foram utilizadas 64 vacas adultas (doadoras de embriões) e não-lactantes da raça Nelore. Todas as doadoras estavam em piquetes de Brachiaria decumbens com suplementação de silagem de milho no cocho para manter o escore corporal (na escala de 1 a 9 , da condição corporal mais leve ou 1, para o animal obeso ou 9, o escore dos animais utilizados variou de 5 a 7). Água e sal mineral foram fornecidos à vontade durante todo o período do experimento.

Após a detecção de cio, foi feita a avaliação ovariana das doadoras por palpação retal e aquelas que apresentaram corpo lúteo normal foram superovuladas no $10^{\circ}(\mathrm{n}=18), 11^{\mathrm{o}}(\mathrm{n}=10), 12^{\mathrm{o}}(\mathrm{n}=26)$ ou $13^{\mathrm{o}}(\mathrm{n}=10)$ dia após a data do cio com $20 \mathrm{ml}$ de Folltropin ${ }^{\circledR}$ (Vetrepharm, Belleville, Canada) ou $10 \mathrm{ml}$ Pluset ${ }^{\circledR}$ (I.F. Serono, Roma, Itália), distribuídos em dosagens decrescentes $(4,0,4,0,3,0,3,0,2,0,2,0,1,0$ e $1,0 \mathrm{ml}$ para o Folltropin e 2,0, 2, $0,1,5,1,5,1,0,1,0,0,5$ e $0,5 \mathrm{ml}$ para o Pluse ${ }^{\circledR}$ ) durante quatro dias em duas aplicações diárias (intercaladas de doze horas). O Folltropin ${ }^{\circledR}$ é um extrato de hormônio folículo estimulante (FSH) obtido de glândulas pituitárias suínas, enquanto o Pluset ${ }^{\circledR}$ é uma mistura com relação definida e constante de FSH e LH extraída de pituitária suína na proporção FSH:LH de 1:1; a atividade biológica do FSH é de $100 \%$, enquanto a do LH é de $25 \%$. Os tratamentos foram designados aleatoriamente às doadoras, segundo um delineamento inteiramente casualizado.

As diferentes dosagens de vitamina A (Roche ${ }^{\circledR}$, São Paulo de 0, 500.000, 1.000 .000 e 1.500.000 UI de vitamina A na forma de palmitato de retinol) foram diluídas em $10 \mathrm{ml}$ de óleo de milho estéril e aplicadas em dose única juntamente com a primeira dose de FSH. A aplicação da vitamina A foi realizada no músculo semimembranoso ou semitendinoso, porém, no lado oposto às injeções superovulatórias. As doadoras foram distribuídas aleatoriamente nos respectivos tratamentos, de acordo com a Tabela 1 . 
A luteólise foi induzida no quarto dia do tratamento de FSH, com uma aplicação de $0,75 \mathrm{mg}$ de cloprostenol sódico (Ciosin ${ }^{\circledR}$, Coopers do Brasil, São Paulo, Brasil), e as doadoras observadas em cio foram inseminadas 12 e 24 horas após o início do cio. Todas as doadoras foram inseminadas pelo mesmo inseminador. O processo da superovulação e aplicação da vitamina A está descrito no esquema abaixo (nesse caso, a coleta está representada 7 dias após o cio superovulatório - dia em que são feitas as inseminações artificiais):

Das 64 doadoras superovuladas, 10, 46 e 8 doadoras foram coletadas, respectivamente, 6,7 e 8 dias após o cio, mediante coleta não-cirúrgica (ELSDEN et al., 1976). O útero de cada doadora foi lavado com 1,0 litro de Dulbecco Modificado (DPBS) (Cultilab, Campinas, SP) e os embriões, coletados em recipientes com filtros de $80 \mu \mathrm{m}$. Todas as coletas foram realizadas pelo mesmo técnico.

A seguir, as estruturas recuperadas foram classificadas quanto ao grau de desenvolvimento em: óvulos, embriões degenerados, mórula, blastocisto inicial, blastocisto, blastocisto expandido e blastocisto eclodido. Os embriões foram classificados segundo o grau de qualidade e considerados viáveis ou não dentro de cada classe de desenvolvimento em: não fertilizado ou óvulo, degenerado, pobre, médio, bom e excelente. A classificação dos embriões foi feita por um único técnico experiente.

A análise do efeito das diferentes dosagens de vitamina A sobre o número de estruturas recuperadas (ER), número de embriões viáveis $(\mathrm{V})$ e porcentagem de embriões viáveis (\% Viáveis) foi realizada pelo procedimento GENMOD (SAS INSTITUTE, 1995), visto que os dados seguem a distribuição de Poisson. Como todas a doadoras já haviam sido coletadas na central antes do início do experimento, utilizouse a proporção entre o número de embriões viáveis da coleta anterior (VA) e o número de estruturas recuperadas da coleta anterior (ERA). A essa proporção deu-se o nome de GPA, que foi usada como covariável para ajustar o modelo. As médias dos tratamentos foram comparadas por contraste (SAS INSTITUTE, 1995).

\section{RESULTADOS E DISCUSSÃO}

O número de embriões viáveis das doadoras que receberam vitamina $\mathrm{A}$ foi maior $(\mathrm{P}<0,0001)$ do que o do tratamento-controle (Tabela 2).

O número de embriões viáveis produzidos pelas doadoras do grupo controle é condizente com vários trabalhos consultados (SANTIAGO et al., 2000; AMARAL et al., 2001; KANZAKI et al., 2001). O aumento de até três embriões viáveis nos grupos suplementados demonstra o efeito da vitamina A na qualidade embrionária. Em épocas de seca, como a da realização do experimento, a suplementação de Vitamina A é ainda mais justificável, do ponto de vista nutricional, para os animais, principalmente quando submetidos a condições estressantes adicionais (superovulação). Justifica-se, portanto, a associação entre a suplementação e o aumento observado na viabilidade dos embriões produzidos.

TABELA 1 - Distribuição das doadoras de acordo com os tratamentos e hormônios aplicados.

\begin{tabular}{cccccc}
\hline \multirow{2}{*}{ Hormônios } & \multicolumn{5}{c}{ Tratamentos (UI de vitamina A) } \\
\cline { 2 - 6 } & $\mathbf{0}^{\mathbf{1}}$ & $\mathbf{5 0 0 . 0 0 0}$ & $\mathbf{1 . 0 0 0 . 0 0 0}$ & $\mathbf{1 . 5 0 0 . 0 0 0}$ & Total \\
\hline Folltropin $^{\circledR}$ & 11 & 13 & 13 & 9 & 46 \\
Pluset $^{\circledR}$ & 4 & 3 & 4 & 7 & 18 \\
\hline Total & 15 & 16 & 17 & 16 & 64 \\
\hline
\end{tabular}

${ }^{1}$ UI de vitamina A na forma de palmitato de retinol (Roche ${ }^{\circledR}$, São Paulo, SP) aplicados i.m. diluídos em $10 \mathrm{ml}$ de óleo de milho estéril

${ }^{2}$ O tratamento com 0 UI de vitamina A consistiu da aplicação de $10 \mathrm{ml}$ de óleo de milho i.m. (grupo controle).

A porcentagem de embriões viáveis das doadoras que receberam vitamina $A$ foi maior $(\mathrm{P}<0,01)$ do que a do tratamento-controle (Tabela 2).
A resposta positiva na viabilidade de embriões bovinos também foi encontrada por Shaw et al. (1995) com a dosagem de 1.000 .000 UI de palmitato 
de retinol, em bovinos suplementados com abóbora (AMARAL et al., 2001)e também em ratas suplementadas com vitamina A injetável (ELMARIMI et al., 1990). Várias podem ser as causas para essa melhora na qualidade: primeiro, com a suplementação de vitamina A injetável, a qualidade do folículo melhora (SCHWEIGERT e ZUCKER, 1988; SCHWEIGERT et al., 1988) e, conseqüentemente, a viabilidade dos embriões das doadoras superovuladas; segundo, a vitamina A pode estimular uma das enzimas-chaves da esteroidogênese denominada Citocromo P450 de clivagem da cadeia lateral (HAYES, 1971; COREY e HAYES, 1972; JAYARAM et al., 1973; GANGULY et al., 1980), aumentando a produção de pregnenolona, precursor da progesterona; terceiro, a vitamina $\mathrm{A}$ modula a atividade da enzima $\Delta^{5}-3 \beta$-hidroxiesteróide desidrogenase (JUNEJA et al., 1966; ISLABÃO, 1982) para a maior conversão de pregnenolona em progesterona, que possivelmente está associada à melhor qualidade embrionária (DYCK et al., 1980; PHARAZYN et al., 1991; JINDAL et al., 1996;
WHALEY et al., 1997) e, por último, a progesterona melhora o ambiente uterino e o suporte nutricional para o desenvolvimento do embrião (THOMAS et al., 1992).

As células ovarianas renovam-se em intervalos freqüentes, o que ocasiona maior demanda de vitamina A em etapas fundamentais da diferenciação celular (HAYES, 1971; COREY e HAYES, 1972; JAYARAM et al., 1973). Em animais superovulados, devido à maior produção de oócitos, pode ocorrer exigência ainda maior de vitamina A nas células ovarianas. Em animais sem suplementação, é possível que a exigência da vitamina A não seja suprida e, conseqüientemente, haja menor número de embriões viáveis (Tabela 2).

A porcentagem de embriões viáveis foi aumentada com a suplementação de vitamina $\mathrm{A}$, porém, o número total de embriões produzidos não foi diferente $(\mathrm{P}>0,05)$ do controle (Tabela 2$)$, significando que a vitamina A melhora a eficiência do processo de tecnologia de embriões colhidos de vacas superovuladas.

TABELA 2 - Número de estruturas recuperadas (médias corrigidas), embriões viáveis e porcentagens de embriões viáveis produzidos pelas doadoras que receberam as diferentes dosagens de vitamina A injetável.

\begin{tabular}{|c|c|c|c|c|c|}
\hline \multirow{2}{*}{ Tratamento } & \multicolumn{2}{|c|}{ Estruturas Recuperadas } & \multicolumn{2}{|c|}{ Embriões Viáveis } & \multirow{2}{*}{ \% Viáveis } \\
\hline & $\mathbf{N}$ & Média \pm DP & $\mathbf{N}$ & Média \pm DP & \\
\hline $0 *$ & 15 & $8,2 \pm 1,9^{\mathrm{a}}$ & 15 & $3,6 \pm 1,9^{\mathrm{a}}$ & $51^{\mathrm{a}}$ \\
\hline $500.000 *$ & 16 & $9,5 \pm 1,9^{\mathrm{a}}$ & 16 & $6,1 \pm 1,9^{b}$ & $57^{\mathrm{b}}$ \\
\hline $1000.000 *$ & 17 & $8,3 \pm 1,9^{\mathrm{a}}$ & 17 & $6,3 \pm 1,9^{b}$ & $63^{\mathrm{b}}$ \\
\hline $1.500 .000 *$ & 16 & $10,5 \pm 1,9^{\mathrm{a}}$ & 16 & $6,7 \pm 1,9^{b}$ & $60^{\mathrm{b}}$ \\
\hline
\end{tabular}

Letras iguais nas colunas não diferem entre si $(\mathbf{P}>0,05)$.

a,b, letras diferentes na coluna de embriões viáveis diferem estatisticamente $(P<0,0001)$.

a, b letras diferentes na coluna \% de embriões viáveis diferem estatisticamente $(P<0,01)$

*UI de vitamina A na forma de palmitato de retinol (Roche ${ }^{\circledR}$, São Paulo, SP), ou veículo, aplicados IM diluídos em $10 \mathrm{ml}$ de óleo de milho estéril.

\section{CONCLUSÕES}

A vitamina A aumenta o número de embriões viáveis sem interferir na quantidade produzida. Sendo as- sim, recomenda-se, principalmente em períodos de carência nutricional, a sua suplementação via injetável como forma de incrementar a produção de embriões de vacas Nelore superovuladas. 


\section{REFERÊNCIAS BIBLIOGRÁFICAS}

AMARAL, B. C. do; SOUZA, J. C. de; LEMOS, F. O. Efeito da suplementação de $3 \mathrm{~kg}$ de abóbora $(\mathrm{Cu}$ cúrbita maxima) na quantidade e qualidade de embriões coletados de vacas doadoras. Revista Brasileira de Reprodução Animal, Belo Horizonte, v. 25, n. 3, p. 331-333, 2001.

COREY, J. E.; HAYES, K. C. Cerebrospinal fluid pressure, growth and hematology in relation to retinol status of the rat in acute vitamin a deficience. Journal of Nutrition, Bethesda, v. 102, n. 12, p. 1585-1593, Dec. 1972.

DYCK, G. W.; PALMER, W. M.; SIMARAKS, S. Progesterone and luteinizing hormone concentration of pregnant gilts on different levels of feed consumption. Canadian Journal of Animal Science, Ottawa, v. 63, n. 4, p. 877-884, Dec. 1980.

EBERHARDT, D. M.; WILL, W. A.; GODKIN, J. D. Retinol administration to superovulated ewes improves in vitro embryonic viability. Biology of Reproduction, Madison, v. 60, n. 6, p. 1483-1487, June 1999.

ELMARIMI, A. A.; HOLDAS JUNIOR, S.; VÉN, E.; IMRIK, P. Effect of vitamin a supplementation on mice embryo production and viability. Reproduction in Domestic Animal, Berlin, v. 25, n. 5, p. 247-248, Oct. 1990.

ELSDEN, R. P.; HASLER, J. F.; SEIDEL, G. E. J. Nonsurgical recovery of bovine eggs. Theriogenology, Worburn, v. 6, p. 523-532, 1976.

GANGULY, J.; RAO, M. R. S.; MURTHY, S. K.; SARADA, K. Systemic mode of action of vitamin A. Vitamin and Hormones, New York, v. 38, p. 1, 1980.

HAYES, K. C. Nutrition Reviews, Amsterdam, v. 29, p. 3-6, 1971.

ISLABÃO, N. Vitaminas: seu metabolismo no homem e nos animais domésticos. 2. ed. São Paulo: Nobel, 1982. $201 \mathrm{p}$.

JAYARAM, M.; MURTHY, S. K.; GANGULY, J. Effect of vitamin A deprivation on the cholesterol side-chain cleavage enzyme activity of testes and ovaries of rats. Biochemical Journal, London, v. 136, n. 1, p. 221-223, 1973.
JINDAL, R.; COSGROVE, J. R.; AHERNE, F. X.; FOXCROFT, G. R. Effect of nutrition on embryonal mortality in gilts: Association with progesterone. Journal of Animal Science, Champaign, v. 74, n. 3, p. 620, Mar. 1996.

JUNEJA, H. S.; MURTHY, S. K.; GANGULY, J. The effect of vitamin A deficiency on the biosynthesis of steroid hormones in rats. Biochemical Journal, London, v. 99, n. 1, p. 138, 1966.

KANZAKI, M. T.; RESENDE, J.; OLIVEIRA, J. V. L.; MOURA, J. C. A.; RIBEIRO FILHO, A. L.; CHALHOUB, M.; GUSMÃO, A. L. Superovulação de vacas nelores através de uma única injeção subcutânea de FSH dissolvido em polivinilpirrolidona. Revista Brasileira de Reprodução Animal, Belo Horizonte, v. 25, n. 3, p. 329-331, 2001.

MCDOWELL, L. R. Vitamins in animal nutrition: comparative aspects to human nutrition. San Diego: Academic, 1989. 486 p.

PHARAZYN, A.; HARTOG, L. A. den; FOXCROFT, G. R.; AHERN, F. X. Dietary energy and protein intake, plasma progesterone and embryo survival in early pregnancy in the gilt. Canadian Journal of Animal Science, Ottawa, v. 71, n. 3, p. 949, Sept. 1991.

SANTIAGO, L. L.; TORRES, C. A. A.; NOGUEIRA, E. T.; SANTOS, A. D. F.; OLIVEIRA, R. J. de; GOMES, L. G.; CARNEIRO NETO, O. A.; MAFFILI, V. L. Classificação das estruturas coletadas em novilhas nelore confinadas superovuladas com doses diferentes de FSH. Viçosa: SBZ, 2000.

SAS INSTITUTE. SAS/STAT user's guide: version 6.12. 4. ed. Cary, 1995. v. 2, 1686 p.

SCHWEIGERT, F. J.; WIERICH, M.; RAMBECK, W. A.; ZUCKER, H. Carotene cleavage activity in bovine ovarian follicles. Theriogenology, Worburn, v. 30, n. 5, p. 923-930, Nov. 1988.

SCHWEIGERT, F. J.; ZUCKER, H. Concentrations of vitamin $A, \beta$-carotene and vitamin $E$ in individual bovine follicles of different quality. Journal of Reproduction and Fertility, Cambridge, v. 82, n. 2, p. 575-579, Mar. 1988.

SHAW, D. W.; FARIN, P. W.; WASHBURN, S. P.; BRITT, J. H. Effect of retinal palmitate on superovulation rate and embryo quality in superovulated cattle. Theriogenology, Worburn, v. 44, n. 1, p. 51-58, July 1995. 
THOMAS, P. G. A.; LESLIE, M. V.; HANSEN, P. J. Retinol binding protein is produced by bovine endometrium and accumulates in uterine secretions in a progesterone-dependent manner. Animal Reproduction Science, Amsterdam, v. 27, n. 1, p. 55-66, Feb. 1992.

WHALEY, S. L.; HEDGPETH, V. S.; BRITT, J. H. Evidence that injection of vitamin A before mating may improve embryo survival in gilts fed normal or high-energy diets. Journal of Animal Science, Champaign, v. 75, n. 4, p. 1071-1077, Apr. 1997.

YAAKUB, H.; O'CALLAGHAN, D.; BOLAND, M. P. Effect of type and quantity of concentrates on superovulation and embryo yield in beef heifers. Theriogenology, Worburn, v. 51, n. 8, p. 1259-1266, June 1999. 